\title{
Consensus methodology to determine minor ailments appropriate to be directed for management within community pharmacy
}

\section{Hamde Nazar ${ }^{\mathrm{a}, *}$}

hamde.nazar@newcastle.ac.uk

\section{Zachariah Nazar}

Andre Yeung

Mike Maguire

Alex Connelly

Sarah P. Slight

aSchool of Pharmacy, King George VI Building, Newcastle University, Newcastle-upon-Tyne, UK

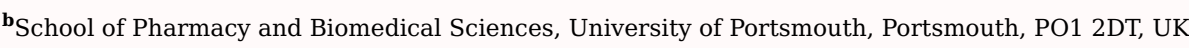

${ }^{c}$ Local Professional Network - Northumberland, Tyne and Wear, NHS England, Newcastle-upon-Tyne, NE15 8NY, UK

${ }^{\mathbf{d}}$ Local Professional Network - Durham, Darlington and Tees, NHS England, Durham, DL3 7DR, UK

enorth East \& North Cumbria Emergency Care Network, North of England Commissioning Support, Durham, DH1 3YG, UK

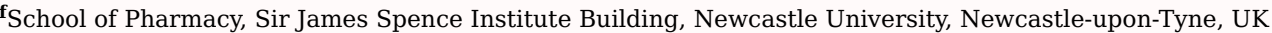

${ }^{*}$ Corresponding author.

\section{Abstract}

\section{Background}

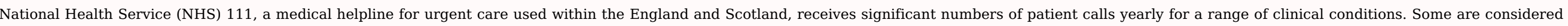

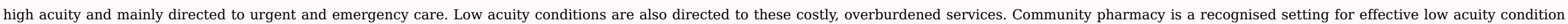
management and could offer an alternative.

\section{Objective}

To design and evaluate a new NHS111 pathway re-directing patients with low acuity conditions to community pharmacy. Methods

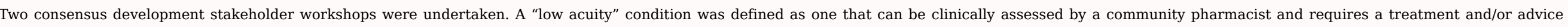

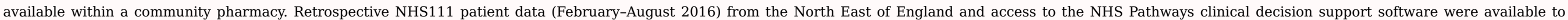
stakeholders. The NHS111 data demonstrated the volume of patient calls for these conditions that could have been redirected to community pharmacy.

Results

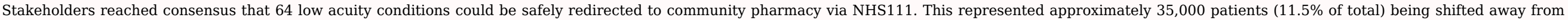

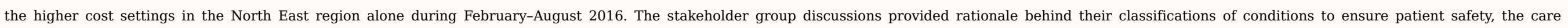
experience and added value.

Conclusions 


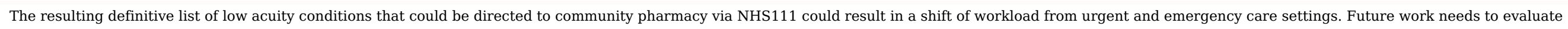
the cost, clinical outcomes, patient satisfaction of a community pharmacy referral service that has the potential to improve integration of community pharmacy in the wider NHS.

Keywords: Minor ailments; NHS 111; Nominal group process; Consensus methodology; Framework analysis

\section{Introduction}

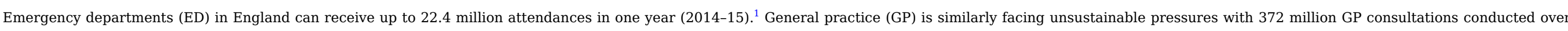

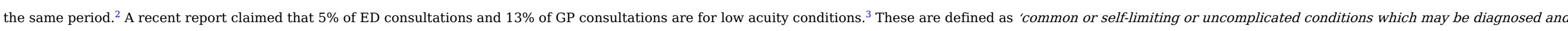
managed without medical (i.e. doctor) intervention', ${ }^{4}$

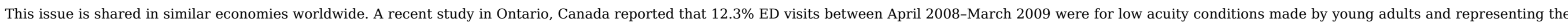
most deprived population. ${ }^{5}$ Another study in Norway reported that $28 \%$ of out-of-hours consultations in November and December 2008 were dedicated to conditions classified as minor ailments. ${ }^{6}$

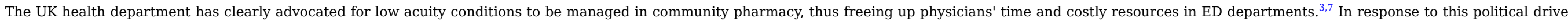

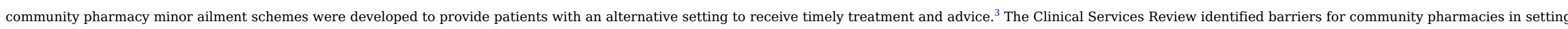
up such schemes, including the lack of digital interoperability that would facilitate information transfer between community pharmacy and the wider NHS. ${ }^{8}$

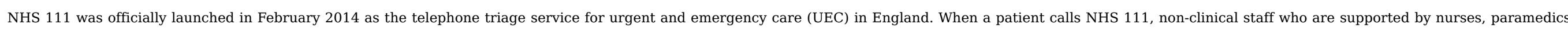

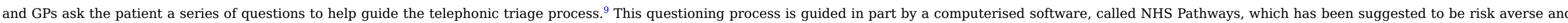
could be improved. ${ }^{9}$

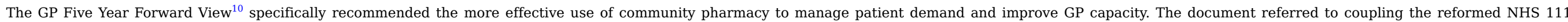

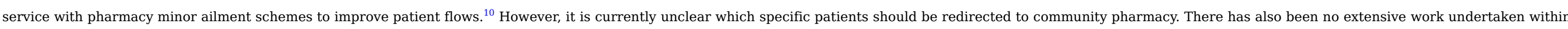
NHS 111 to establish community pharmacy as a safe and appropriate alternative pathway of care for low acuity patients away from overburdened and costly UEC.

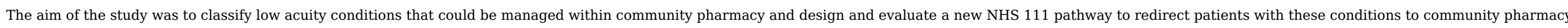
away from UEC.

\section{Methods}

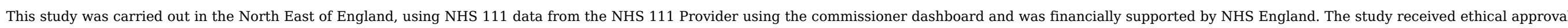
from the Research Ethics Committee of the Durham University School of Medicine, Pharmacy and Health (ref no. ESC2/2016/PP03) to conduct two consensus development workshops.

\subsection{Participants}

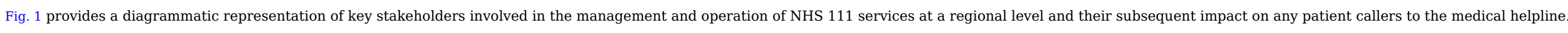




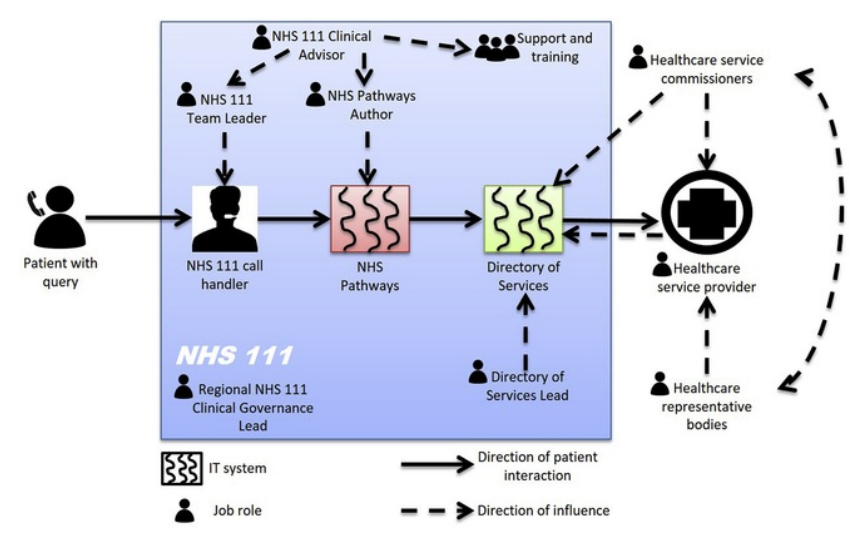

Fig. 1 The stakeholder roles and influences within the NHS 111 system that interact at every patient call.

\section{alt-text: Fig. 1}

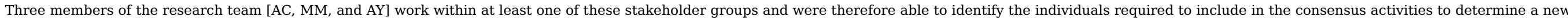

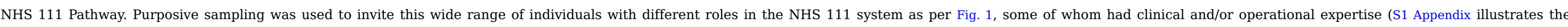

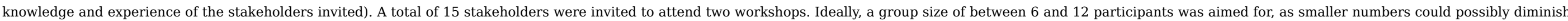

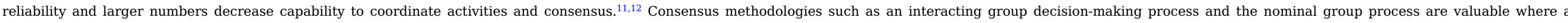

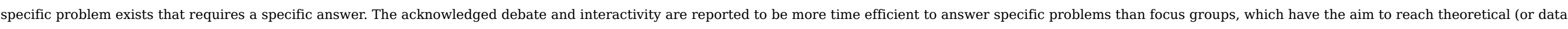

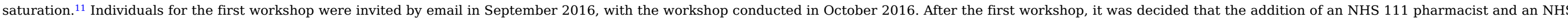

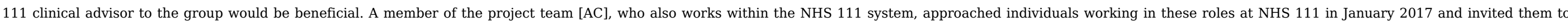
attend the second workshop, which was conducted in February 2017.

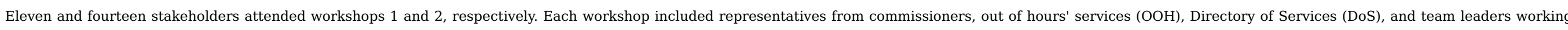
within the NHS 111 system (Table 1).

Table 1 The attendance of key stakeholders at the two workshops.

\begin{tabular}{|c|c|c|c|}
\hline Stakeholders & Workshop 1 & Workshop 2 & Comments \\
\hline Community pharmacists & $2+3^{*}$ & $1^{\wedge}+3^{*}$ & \\
\hline DoS Lead, NHS 111 & $1^{*}$ & $1^{*+1}$ & $\begin{array}{l}\text { The national DoS lead was invited } \\
\text { and attended for learning and } \\
\text { sharing of good practice purposes }\end{array}$ \\
\hline NHS 111 Team leader & 1 & $1^{\wedge}+1$ & $\begin{array}{l}\text { One of these participants was the } \\
\text { NHS } 111 \text { Team manager }\end{array}$ \\
\hline OOH GP Clinician & 2 & $2^{\wedge}$ & \\
\hline $\begin{array}{l}\text { Regional NHS } 111 \text { Clinical } \\
\text { lead }\end{array}$ & 1 & $1^{\wedge}$ & \\
\hline NHS 111 Pharmacist & 0 & 1 & \\
\hline $\begin{array}{l}\text { Regional NHS } 111 \text { Clinical } \\
\text { Advisor }\end{array}$ & 0 & 1 & \\
\hline NHS Pathways authors & 0 & 0 & \\
\hline $\begin{array}{l}\text { Commissioners/ } \mathrm{OOH} \\
\text { service providers }\end{array}$ & 1 & $1^{\wedge}$ & \\
\hline Total & 11 & 14 & \\
\hline
\end{tabular}

1 , and shaded boxes indicate representatives with clinical expertise) 
At both workshops, participants were informed of the key objectives and format. Written consent for the audio recording of discussions was obtained prior to commencement of each workshop.

\subsection{Workshop 1: identification of low acuity patient conditions}

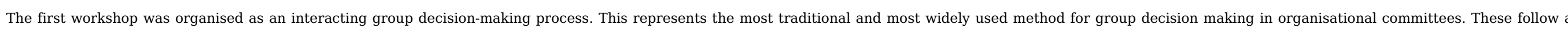

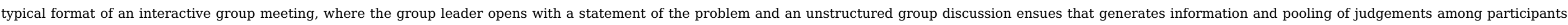

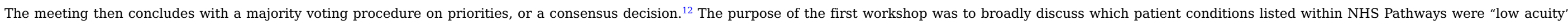
conditions and could be potentially re-directed to the community pharmacy.

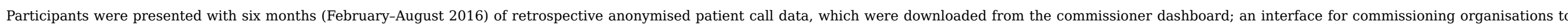
access data about service usage, demand and supply. ${ }^{13}$ This equated to approximately 305,646 NHS 111 calls.

These NHS 111 data contained information about:

(1) The patient's presenting condition or "Symptom Group" (SG code) e.g., coughs;

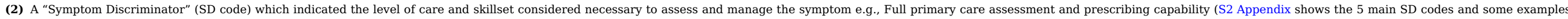
of sub-types); and

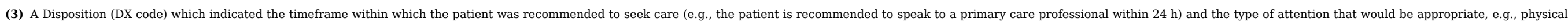
attendance presentation to a healthcare professional (S3 Appendix shows the timeframe and skillset that are recommended).

To summarise, this generated a SG/SD/DX combination, as illustrated in Fig. 2, which then guided the call handler to recommend a particular course of action. ${ }^{13}$ 


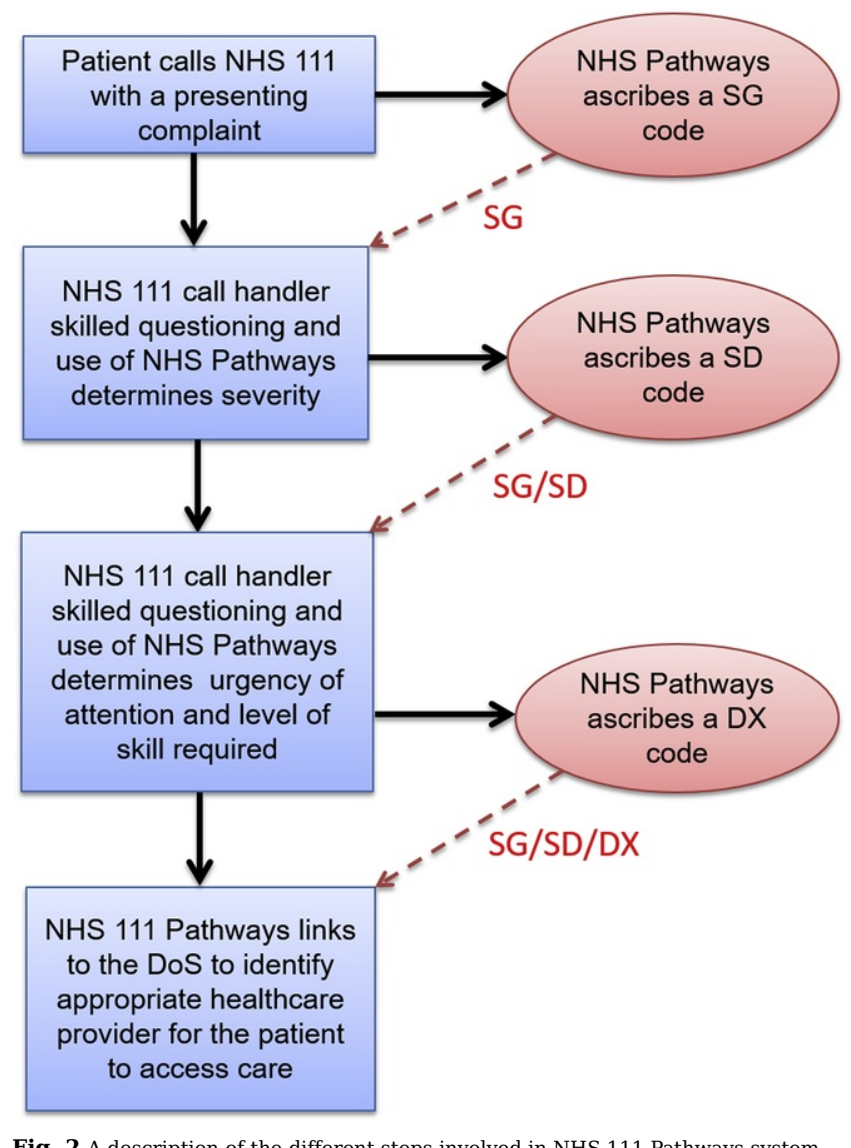

Fig. 2 A description of the different steps involved in NHS 111 Pathways system.

alt-text: Fig. 2

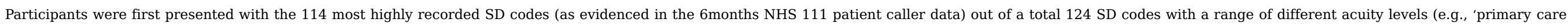

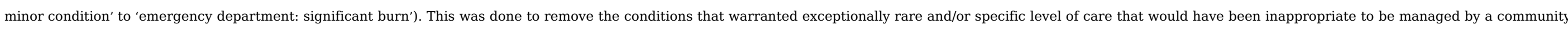

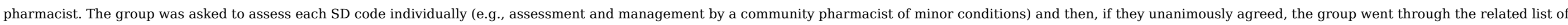

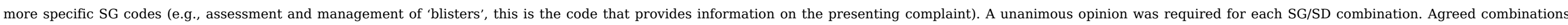
were entered onto a live Excel spreadsheet that was projected onto one wall of the meeting room for the group to view and update accordingly.

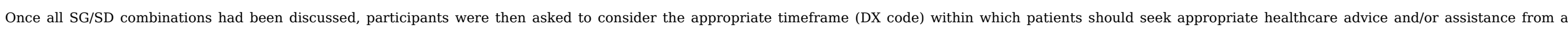
community pharmacy for each combination. The timeframe needed to be appropriate across all identified combinations.

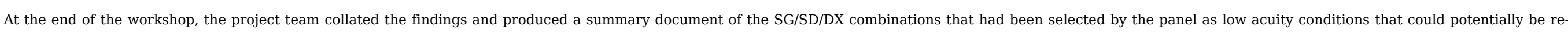
directed to the community pharmacy.

The research team filtered the NHS 111 data (February-August 2016) to identify the volume of calls attributed to this list of consensus SG/SD/DX combinations.

After the workshop, this summary was sent to participants electronically, and they were asked to provide comment on the accuracy of the recording of the events and findings. 


\subsection{Workshop 2: clinical validation of the low acuity patient conditions}

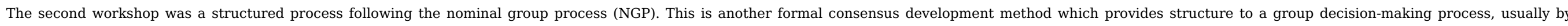

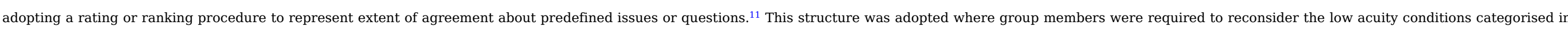

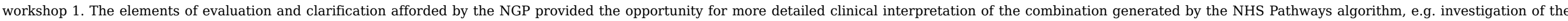
call handler's specific questions, and patient answers to trigger the code, thereby clinically assessing the appropriateness of management by a community pharmacist.

The overall goal of the second workshop was to clinically validate the low acuity conditions identified in the first workshop.

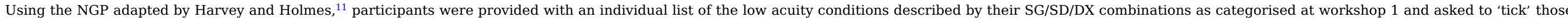

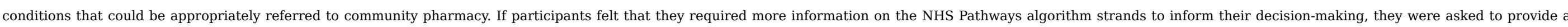

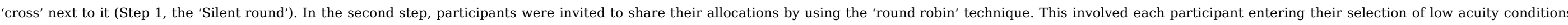

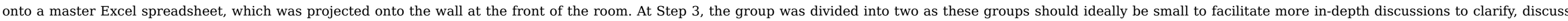

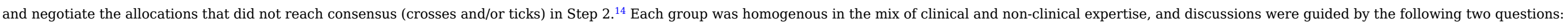

1. Does the assessment for this condition fall within the competence of a community pharmacist?

2. Is the medicinal product or healthcare advice that is required to manage the condition available from a community pharmacy?

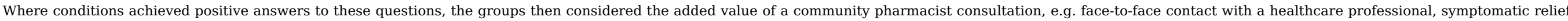
with a pharmacist recommended non-prescription product, and discussed the potential of any patient safety issues that could arise.

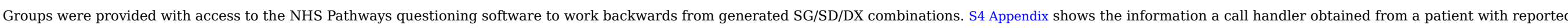

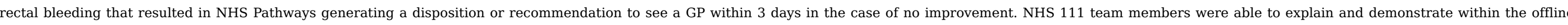

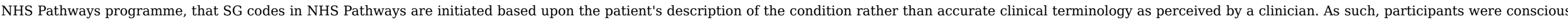

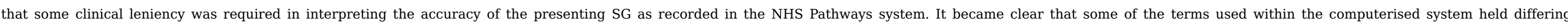

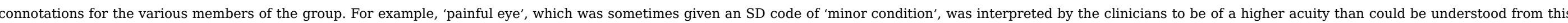

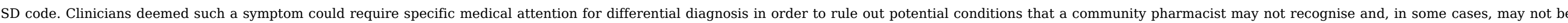

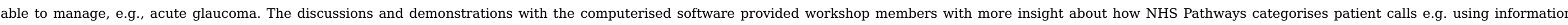

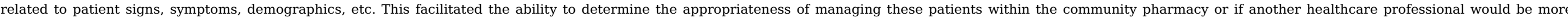
appropriate.

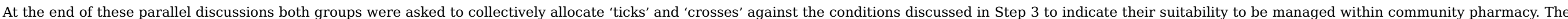
lists from both groups were compiled, and the low acuity conditions that achieved consensus across the two groups represented the group decision..$^{13}$ (This should be reference 15 not 13.$)$

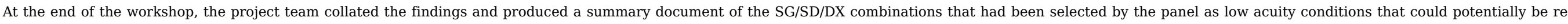
directed to the community pharmacy.

Again, the research team used the final list of low acuity conditions to identify the volume of calls attributed to the consensus SG/SD/DX combinations.

\subsection{Data analysis}

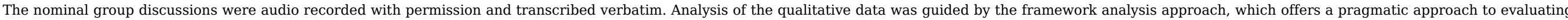
qualitative data. ${ }^{16}$

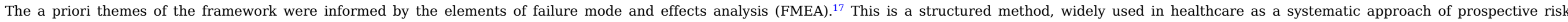




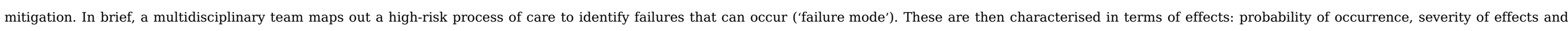
detectability. A risk priority is calculated for each failure mode that then guides the prioritisation of actions and recommendations to prevent or mitigate against it. ${ }^{18}$

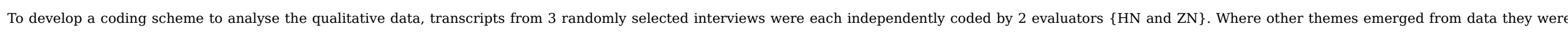

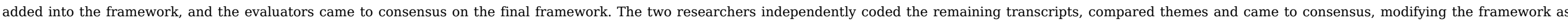
needed to ensure convergence and divergence of the thematic coding scheme.

\subsection{Notes on methodology and analysis}

In order to assure trustworthiness of this study as recommended by Lincoln and Guba, ${ }^{19}$ the following strategies have been employed during data collection and analysis:

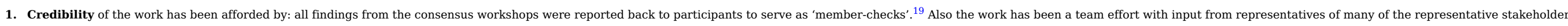
groups involved in the consensus workshops.

2. The level of detail, which can be described as 'thick description, ${ }^{19}$ provided with regards to terminology, data in NHS 111 , transparency of the filtering process with extensive tables in the appendices, will facilitate transferability.

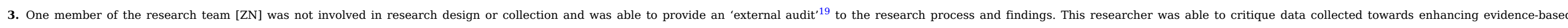
discussions and conclusions and therefore enhancing dependability of the study findings.

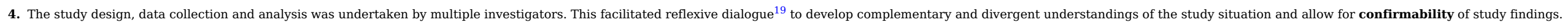

\section{Results}

\subsection{Workshop findings}

\subsubsection{Workshop 1: the low acuity patient conditions}

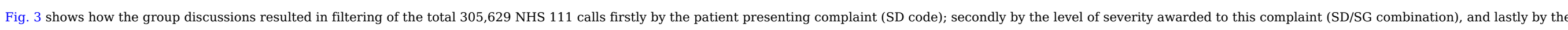
recommended timeframe the patient should seek care (DX code).

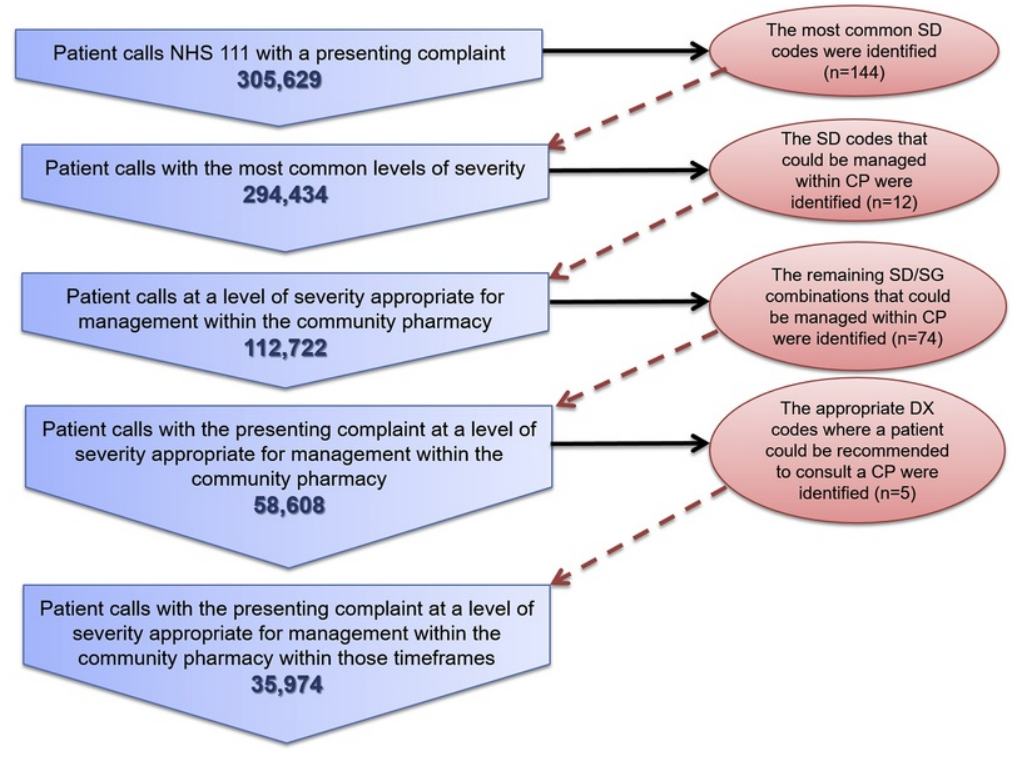




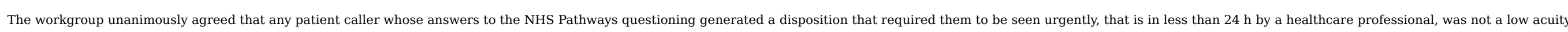
case appropriate for referral to community pharmacy (highlighted in S3 Appendix).

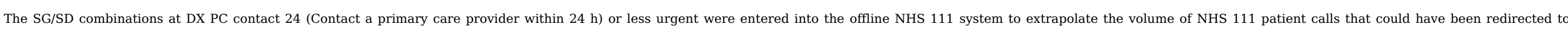

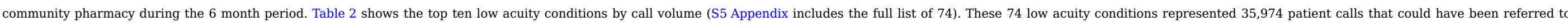
community pharmacy over the 6 month period in the North East (NE) of England.

Table 2 The volume of NHS 111 patient calls attributable to the top ten identified low acuity conditions. (SG: Symptom Group, SD: Symptom Descriptor, PC: primary care, NE: North East).

\section{alt-text: Table 2}

SG

\section{Repeat Prescription \\ Earache}

Cough

Skin rash

Diarrhoea

Sore throat

Repeat Prescription

Blisters

Headache

Lower back pain

Total

\section{SD}

PC repeat prescription, urgent

PC full primary care assessment and prescribing capability

PC full primary care assessment and prescribing capability

PC full primary care assessment and prescribing capability

PC full primary care assessment and prescribing capability

PC full primary care assessment and prescribing capability

PC repeat prescription, routine

PC full primary care assessment and prescribing capability

PC full primary care assessment and prescribing capability

PC full primary care assessment and prescribing capability
Approx. no. of NHS 111 patient calls (Feb-Aug 2016 in NE England) (\%)

\begin{tabular}{|l|}
\hline $6812(2.2)$ \\
\hline $2874(0.9)$ \\
\hline $2582(0.8)$ \\
\hline $2554(0.8)$ \\
\hline $2152(0.7)$ \\
\hline $4978(1.6)$ \\
\hline $1876(0.6)$ \\
\hline $1572(0.5)$ \\
\hline $1496(0.5)$ \\
\hline $1464(0.5)$ \\
\hline
\end{tabular}

$28,360(9.3)$

\subsubsection{Results from workshop 2: the clinically validated low acuity conditions}

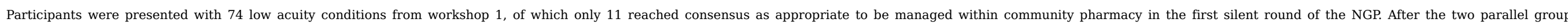

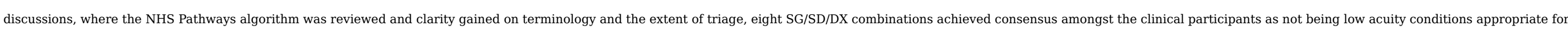

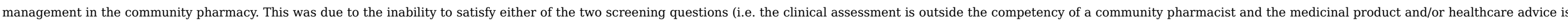
not available at the pharmacy) (Table 3).

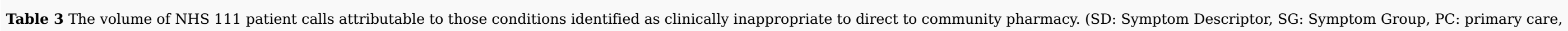
NE: North East). alt-text: Table 3

$$
\text { SG Descriptor }
$$

Abdominal pain
SD Descriptor

PC full primary care assessment and prescribing capability
Approx. no. of NHS 111 patient calls (Feb-Aug 2016 in NE England) 
Eye, painful

Eye, painful

Eye, visual loss or disturbance

Eye, visual loss or disturbance

Head, facial or neck injury, blunt

Mental health problem

Pain and/or frequency passing urine

\section{Total}

PC extended ophthalmic assessment and management capability, minor condition

PC assessment and management capability, minor condition

PC extended ophthalmic assessment and management capability, minor condition

PC assessment and management capability, minor condition

PC full primary care assessment and prescribing capability

PC anxiety/panic

PC assessment and management capability, minor condition
0

0

0

414

0

0

700

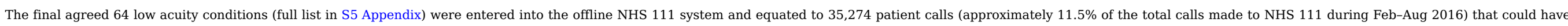
been referred to community pharmacy on an annual basis in the North East alone.

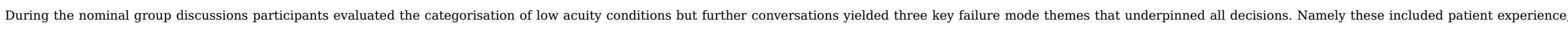

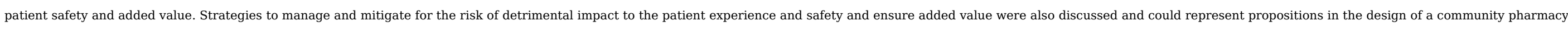
referral service. These themes are explored further during the discussion.

\section{Discussion}

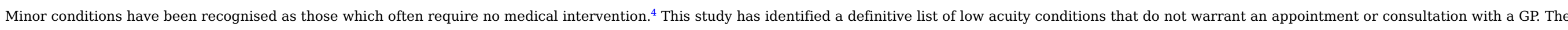

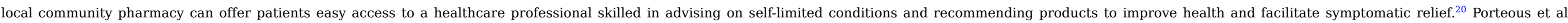

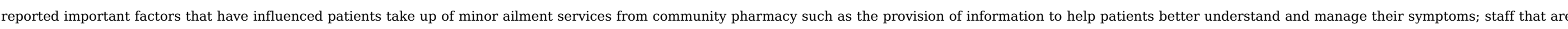

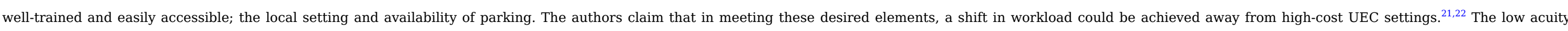

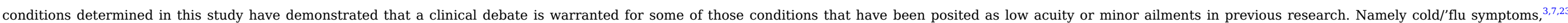
cough, $3,7,20,23-25$ earache, ${ }^{5,23,24}$ eye problems, ${ }^{3,7,20,26}$ have all been classified as minor ailments in published work with little clinical rationalisation.

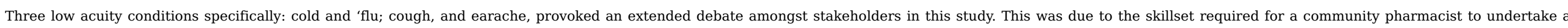

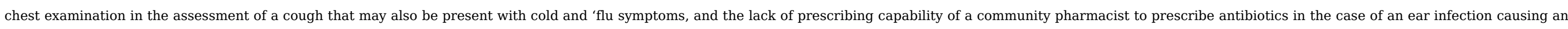

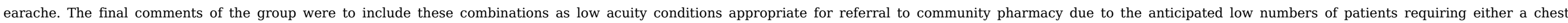

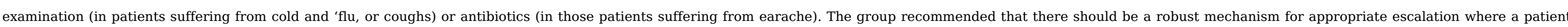

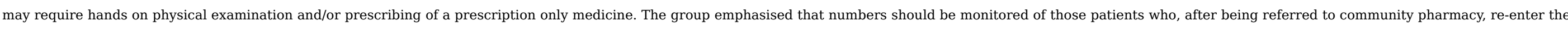
system via the escalation procedure, which may highlight inefficiency, cost-ineffectiveness and a detrimental impact on patient care and experience.

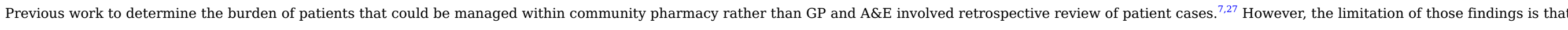

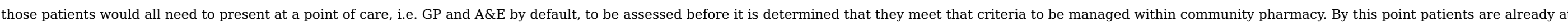

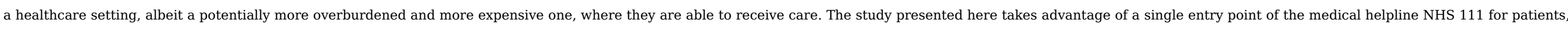

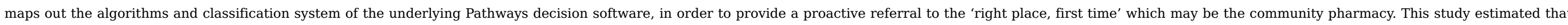

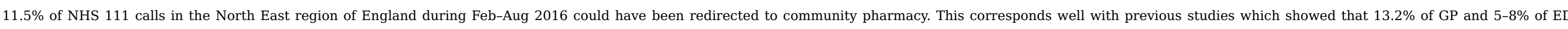

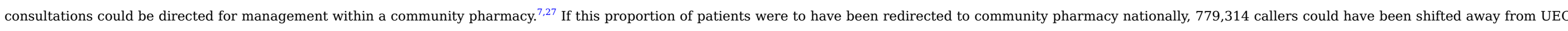

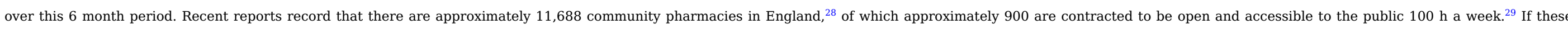

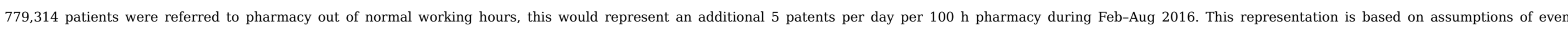



service is implemented.

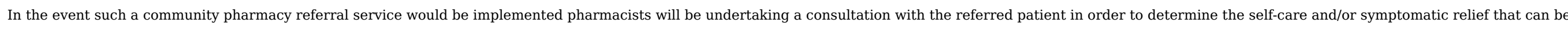

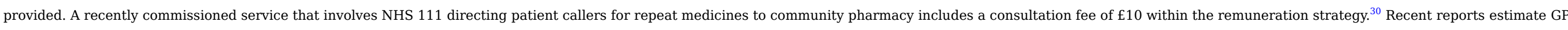

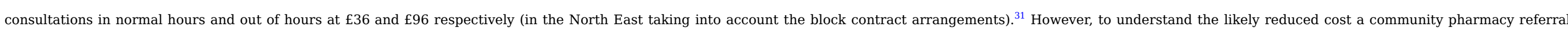

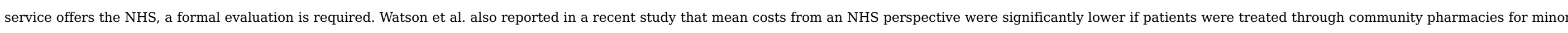

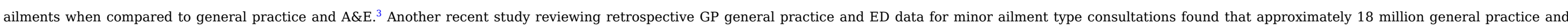

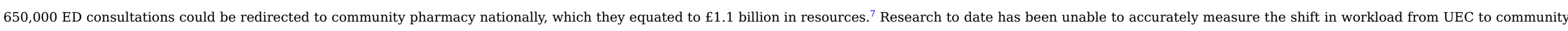

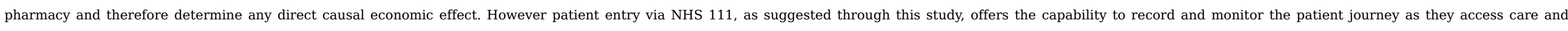
therefore potentially undertake a cost-effectiveness analysis.

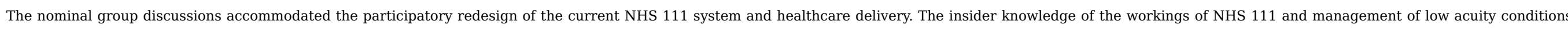

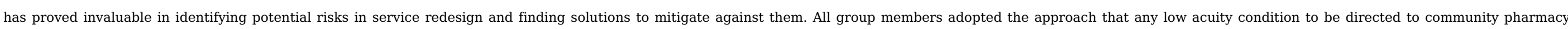

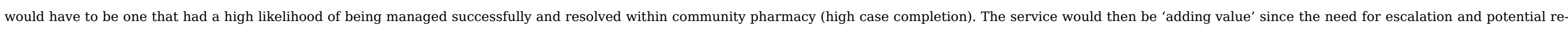

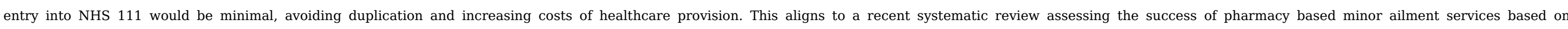

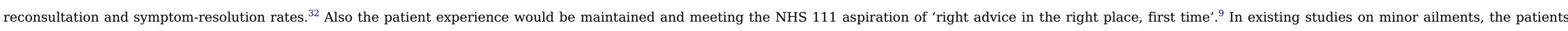

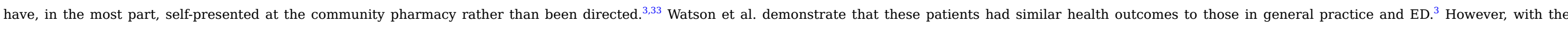

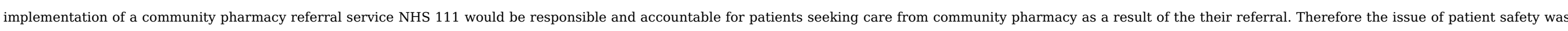

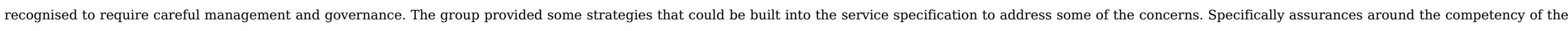

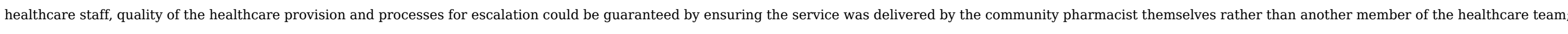

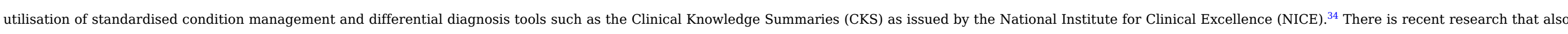

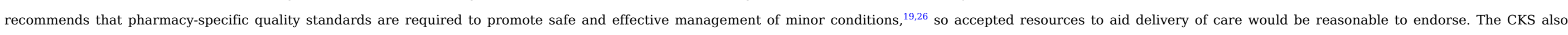

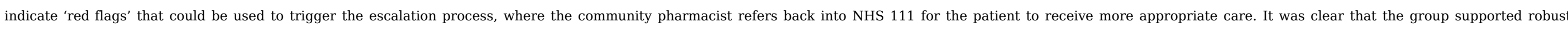

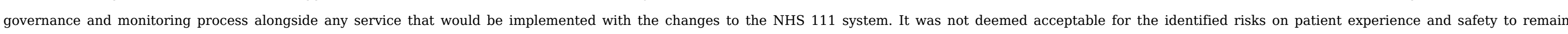

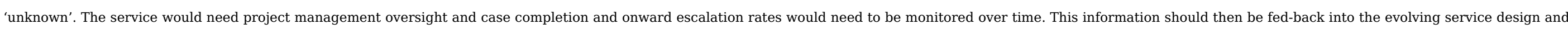

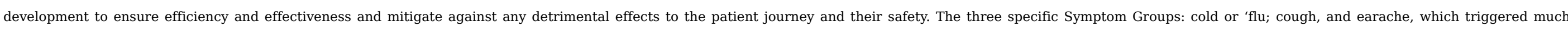

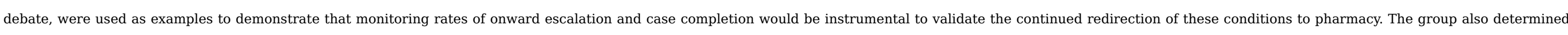

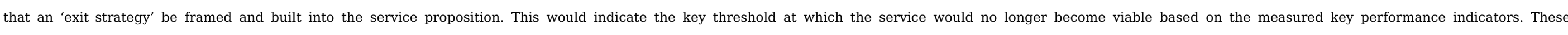

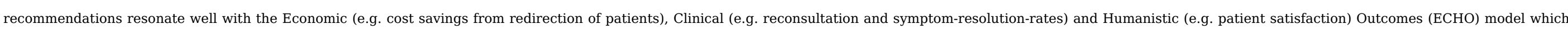
consider the value of a pharmaceutical product or service based on the respective variables. ${ }^{35}$

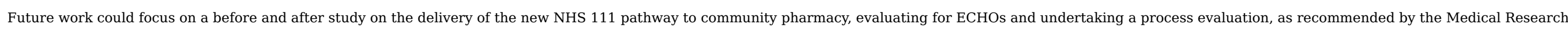
Council for evaluating complex interventions, ${ }^{36}$ to further understand how the service context, implementation and delivery impact upon service success.

\subsection{Limitations}

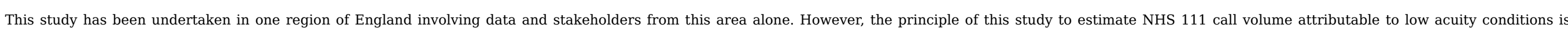

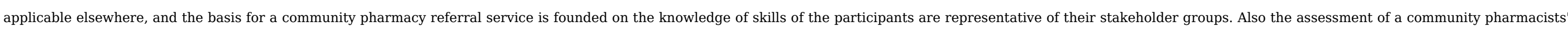

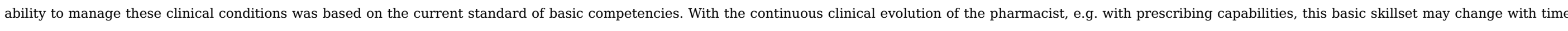

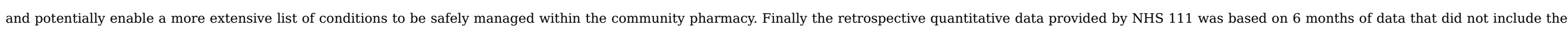




\title{
5 Conclusion
}

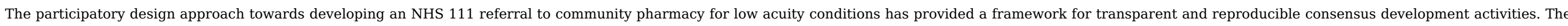

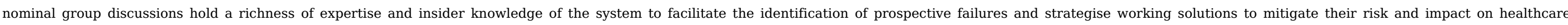

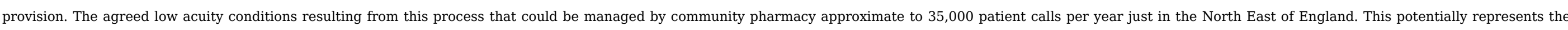

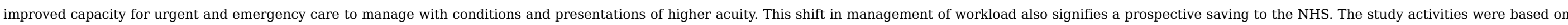

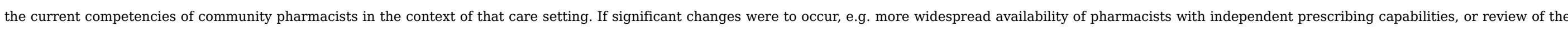
current mechanism of commissioning and supporting community pharmacy contractual services, then this definitive list would need to be revised and updated.

\section{Funding}

This research did not receive any specific grant from funding agencies in the public, commercial, or not-for-profit sectors.

\section{Acknowledgements}

\author{
None.
}

\section{S1 Appendix. The stakeholders identified with technical and clinical expertise of care provision via NHS 111}

\author{
Stakeholders \\ Knowledge and experience \\ Community pharmacists (Clinical) \\ Experience of frontline community pharmacy work and operation, and of managing and referring self-presenting patients with low acuity conditions \\ Knowledge of the types of low acuity conditions patients self-present at community pharmacy on a daily basis; awareness of the baseline competence of a community \\ pharmacist and when patients should be referred to another healthcare professional. \\ NHS 111 Clinical advisor (Clinical) \\ Experience of clinical decision-making; managing risk through telephone triage and supporting non-clinical staff within the call centre. \\ NHS 111 pharmacist (Clinical) \\ Knowledge of clinical assessment and clinical remit of healthcare providers within the NHS 111 urgent and emergency care system. \\ Out of hours' clinicians (Clinical) \\ Experience of providing specialised pharmacy services currently integrated into NHS 111 for urgent and emergency care. \\ Knowledge of the baseline competence of a community pharmacist and when patients should be referred to another healthcare professional. \\ Experience of frontline urgent and emergency healthcare provision across the spectrum of acuity of patient conditions. \\ Knowledge of the clinical assessment of patients with different levels of acuity and their subsequent healthcare needs to help identify what is possible for a pharmacist to \\ undertake safely. \\ NHS 111 team leaders (Non-clinical) \\ Experience of managing patient calls for conditions of all levels of acuity and directing these calls to appropriate healthcare providers by using the NHS Pathways \\ algorithms. \\ Knowledge of the technical terminology, skilled questioning and technical operation of NHS Pathways. \\ Regional NHS 111 Directory of \\ Services lead (Non-clinical) \\ Experience of managing the Directory of Services and analysing the data returned through NHS Pathways. Extensive experience of working within models of integrated \\ urgent care and with technical development and adaptation of NHS Pathways. \\ Knowledge of interpreting DoS data and the NHS Pathways algorithms, terminology and correct operation. \\ Regional NHS 111 clinical lead \\ (Clinical) \\ Experience of managing the clinical governance structures that take into account national guidance and local commissioner requirements to support safe and appropriate \\ services provided via NHS 111; reviewing NHS 111 call data (activity, nature, etc) and responding to serious incidents that are reported. \\ Knowledge of the urgent care landscape including local provider organisations, all urgent care services and local practices; of the nature and consequences of incidents that \\ have posed risk to patient safety. \\ NHS Pathways authors (Non-clinical) \\ Experience of frontline healthcare as well as extensive knowledge of urgent and emergency care. They have comprehensive experience of developing the NHS Pathways \\ algorithms and mechanisms for generating recommendations of referrals and determining level of urgency based on the most recent clinical evidence available. \\ Knowledge of the operation and creation of the NHS Pathways algorithms and the technical terminology used within it. They have a wider knowledge of the direction of \\ Knowledge of the operation and creation of the NHS Pathways algorithms and the technical terminology used within it. They have a wider knowledge
urgent and emergency care and the consequences of the incidents that have been reported through NHS Pathways that could pose a risk to patients.
}


Commissioners of NHS 111 and an out of hours' service provider (Clinical)
Experience of reviewing and evaluating healthcare services for their efficiency and effectiveness of care provision; monitoring performance and managing the portfolio of

Knowledge of the urgent care landscape including local provider organisations, all urgent care services and local practices
Knowailable to patients and the public.

\section{S2 Appendix. The NHS Pathways five main types of Symptom Discriminators (SD)}

\begin{tabular}{|c|c|c|}
\hline $\begin{array}{l}\text { Symptom } \\
\text { Discriminator }\end{array}$ & Sub-type & Explanation \\
\hline Ambulance & $\begin{array}{l}\text { Examples (non- } \\
\text { exhaustive): } \\
\text { Acute coronary } \\
\text { syndrome } \\
\text { Septicaemia } \\
\text { Compound fracture } \\
\text { Shock }\end{array}$ & $\begin{array}{l}\text { These are diagnosis or symptom-specific and of high clinical acuity. They are used by ambulance services to help determine the skill set and resources required when } \\
\text { attending } 999 \text { calls. }\end{array}$ \\
\hline \multirow[t]{3}{*}{$\begin{array}{l}\text { Emergency } \\
\text { Department }\end{array}$} & $\begin{array}{l}\text { Full ED assessment } \\
\text { and management } \\
\text { capability }\end{array}$ & $\begin{array}{l}\text { This means the capability to perform a full clinical assessment of the symptom, as specified by the SG, at the skill set of an emergency department, and to provide } \\
\text { appropriate investigation and definitive management without the need, in most cases, for onward referral. For example, an MIU or WIC without suitable imaging } \\
\text { facilities should not accept this SD when combined with, e.g., SG 'Head, Facial or Neck Injury, Blunt'. }\end{array}$ \\
\hline & $\begin{array}{l}\text { ED management, } \\
\text { significant burn }\end{array}$ & $\begin{array}{l}\text { This means the capability to perform a full clinical assessment and immediate management of deep (partial or full-thickness) but not extensive (i.e. less than } 20 \% \text { ) } \\
\text { thermal and chemical burns, including burns to areas such as head, neck, hands/feet or joints. Onward referral to a specialist burns unit may be required following } \\
\text { assessment and immediate management. }\end{array}$ \\
\hline & $\begin{array}{l}\text { Full ophthalmic ED } \\
\text { assessment and } \\
\text { management } \\
\text { capability }\end{array}$ & $\begin{array}{l}\text { This means the capability to perform assessment and definitive management of isolated eye problems, e.g. welding flashes, foreign body or contact lens problems, } \\
\text { which require slit-lamp examination and ED ophthalmological skills. This may be part of a general ED, specialist eye hospital ED or a separate unit, e.g. a WIC or MIU } \\
\text { with appropriate equipment and expertise. }\end{array}$ \\
\hline \multirow[t]{5}{*}{ Primary Care } & $\begin{array}{l}\text { Full primary care } \\
\text { assessment and } \\
\text { prescribing capability }\end{array}$ & $\begin{array}{l}\text { This means a practitioner with the capability to perform a full clinical assessment of } \\
\text { Primary Care conditions within the SG. The practitioner should be able to prescribe for and manage the conditions and arrange investigations, admission or referral for } \\
\text { specialist opinion if required. }\end{array}$ \\
\hline & $\begin{array}{l}\text { Full mental health } \\
\text { assessment and } \\
\text { prescribing capability }\end{array}$ & $\begin{array}{l}\text { This means a practitioner with the capability to perform a full clinical assessment of mental health problems within the SG. The practitioner should be able to prescribe } \\
\text { for and manage conditions and arrange admission if required. }\end{array}$ \\
\hline & $\begin{array}{l}\text { Full dental } \\
\text { assessment and } \\
\text { prescribing capability }\end{array}$ & $\begin{array}{l}\text { This means the capability to perform a full clinical assessment of dental conditions within the SG. The practitioner should be able to prescribe for and manage dental } \\
\text { conditions relating to the SG and to arrange investigations, admission or referral for specialist opinion if required. }\end{array}$ \\
\hline & $\begin{array}{l}\text { Full obstetric } \\
\text { assessment and } \\
\text { management } \\
\text { capability }\end{array}$ & $\begin{array}{l}\text { This means a Registered Midwife or Medical Practitioner, who can provide assessment and advice for pregnancy-related problems within the Symptom Group and } \\
\text { arrange investigation and admission if required. }\end{array}$ \\
\hline & $\begin{array}{l}\text { Assessment and } \\
\text { management } \\
\text { capability, minor } \\
\text { condition }\end{array}$ & $\begin{array}{l}\text { This means a healthcare professional, e.g. an optician or pharmacist, with the capability to clinically assess and manage specific conditions within the SG that are } \\
\text { unlikely to require prescription medication, further investigation or onward referral. }\end{array}$ \\
\hline Skill Set specific & $\begin{array}{l}\text { Examples (non- } \\
\text { exhaustive): } \\
\text { Urinary catheter } \\
\text { management } \\
\text { capability } \\
\text { Management of }\end{array}$ & These indicate the Primary Care skillset required to manage specific conditions within the SG. \\
\hline
\end{tabular}


capability

Diagnosis/symptom- Examples (nonexhaustive):

Wound, complex

Subungual

haematoma

Loose/damaged

plaster

Sexually transmitted

infection
These enable EDs and Primary Care facilities to determine whether they are equipped to provide assessment and definitive management of specific conditions within the SG, since it is appreciated that different facilities will have different skill sets and resources.

S3 Appendix. An example NHS Pathways consultation report generated for a patient caller calling NHS 111 with rectal bleeding. 


\section{Consultation Report}

Case ID c62711e1-3438-4234-85e9-906ec7dc180

Created on 23/01/2017 15:38:48

Pathways v12.1.0

PATIENT:

TELEPHONE:

AGE GROUP:

GENDER:

PARTY:

NOTES:

SKILLSET:

SKILLSET:
CALL HANDLER USER ID:

CALLHATOER USER ID: TEST_USER1

PATHWAY: PW846 - Rectal Bleeding

Dx16- If symptoms dont improve, or go away and come back
get in touch with the GP practice within 3 working days.

$\begin{array}{ll}\text { SELECTED SERVICE: } & \text { 103595, UCC: UHND Urgent Care Centre, } \\ \text { DOS TRANSACTIONID: } & \text { dCSD59ec-a891-1C30-8206-10cb7fod9taf }\end{array}$

\section{CONSULTATION SUMMARY:}

Medical assessment of problem in last 6 months

Wedical assess to touch

Wliness - rectal bleeding

\section{PATHWAYS ASSESSMENT:}

An injury or health problem was the reason for the contact.

Heavy bleeding had not occurred in the previous 30 minutes.

An illness or health problem was the main problem. - rectal bleeding

The individual was not fighting for breath.

The main reason for the assessment was not a heart attack, chestupper back pain, probable stroke, recent

filseizure or suicide attempt.

The main reason for contact was not new confusion, declared diabetic hypo/hyperglycaemia, a probable allergic

The skin on the torso felt normal, warm or hol

There was no abdominal pain.

The individual had not passed a black, tarry bowel motion.

The rectal bleeding was not constant

The individual had not passed red blood in a bowel motion.

There were no splashes of blood in the tollet after defaecation.

There were no streaks of blood on the toilet paper after defaecation.

A sexual assault had not occurred.

orvising or abnormal bleeding within the previous 2 weeks.

There was no new painful anal or perianal lump.

There was no analrectal pain on defaecation.

The problem had been assessed within the previous 6 month

ADVICE GIVEN:

alt-text: Image 2 


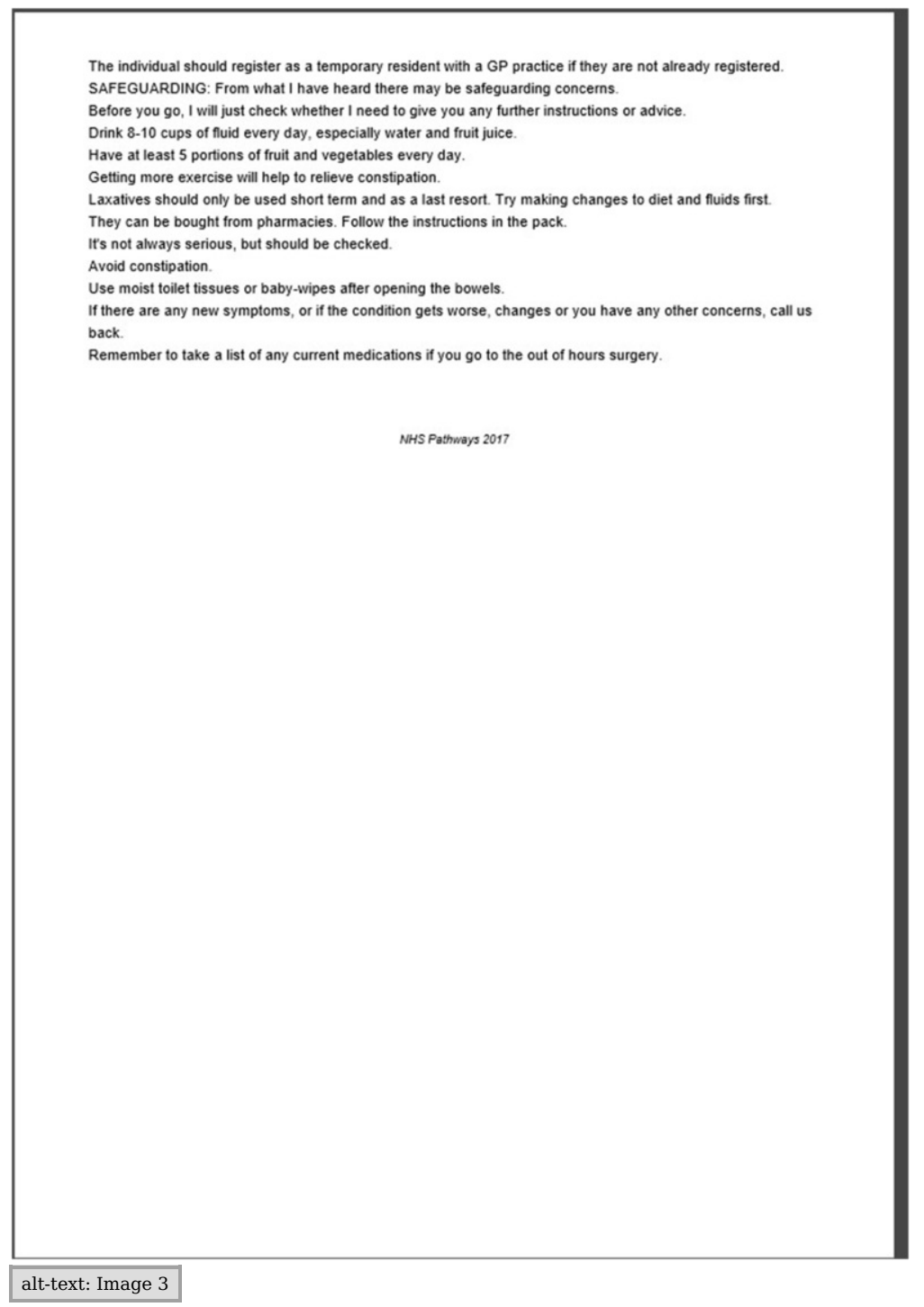

S4 Appendix. NHS Pathways core dispositions (DX codes) that indicate timeframe and most appropriate healthcare setting for patient callers (those highlighted in boldblue are those receiving consensus as appropriate for referral to community pharmacy) 


\section{Pharmacy}

MUST contact own GP 3 days

PC contact 24 h

PC contact $12 \mathrm{~h}$

PC contact $6 \mathrm{~h}$

PC contact $2 \mathrm{~h}$

PC speak to $24 \mathrm{~h}$

PC speak to $12 \mathrm{~h}$

PC speak to $6 \mathrm{~h}$

PC speak to $2 \mathrm{~h}$

PC speak to $1 \mathrm{~h}$

ED $1 \mathrm{~h}$

ED: Emergency Department

ED $4 \mathrm{~h}$

No action taken

Speak to midwife

Optician

Emergency contraception 2 and $12 \mathrm{~h}$

Dental

Repeat contact

Ambulance required

GUM clinic

GUM: Genitourinary clinic

Service location information

H\&SI/specific disposition

H\&SI: Health and social information

S5 Appendix. The identified SG(Symptom Group)/SD(Symptom Descriptor) combinations achieving consensus in workshops 1 and 2 as appropriate for management within community pharmacy and the associated volume of patient callers filtered by the PC (primary care) contact 24 disposition threshold. 


\begin{tabular}{|c|c|c|c|c|c|}
\hline & & codes & & & \\
\hline Abdominal pain & PC full primary care assessment and prescribing capability & 7104 & 286 & Removed & $\begin{array}{l}\text { Not appropriate for community } \\
\text { pharmacy }\end{array}$ \\
\hline Acne, spots and pimples & PC assessment and management capability, minor condition & 30 & 24 & $\checkmark$ & \\
\hline Acne, spots and pimples & PC full primary care assessment and prescribing capability & 14 & 14 & $\checkmark$ & \\
\hline Allergic reaction & PC assessment and management capability, minor condition & 50 & 42 & $\checkmark$ & \\
\hline Allergic reaction & PC full primary care assessment and prescribing capability & 900 & 144 & $\checkmark$ & \\
\hline Ankle or foot pain or swelling & PC full primary care assessment and prescribing capability & 3162 & 912 & $\checkmark$ & \\
\hline Arm, pain or swelling & PC full primary care assessment and prescribing capability & 2126 & 654 & $\checkmark$ & \\
\hline Athlete's foot & PC assessment and management capability, minor condition & 2 & 2 & $\checkmark$ & \\
\hline Athlete's foot & PC full primary care assessment and prescribing capability & 14 & 10 & $\checkmark$ & \\
\hline Bites or stings, insect or spider & PC full primary care assessment and prescribing capability & 2302 & 16 & $\checkmark$ & \\
\hline Bites or stings, insect or spider & PC minor injury & 0 & 0 & Removed & Zero NHS 111 calls \\
\hline Blisters & PC full primary care assessment and prescribing capability & 4832 & 1572 & $\checkmark$ & \\
\hline Cold or flu & PC full primary care assessment and prescribing capability & 2086 & 744 & $\checkmark$ & \\
\hline Constipation & PC full primary care assessment and prescribing capability & 2178 & 486 & $\checkmark$ & \\
\hline Cough & PC full primary care assessment and prescribing capability & 5384 & 2582 & $\checkmark$ & \\
\hline Diarrhoea & PC full primary care assessment and prescribing capability & 7412 & 2152 & $\checkmark$ & \\
\hline Ear discharge or ear wax & PC assessment and management capability, minor condition & 12 & 10 & $\checkmark$ & \\
\hline Earache & PC assessment and management capability, minor condition & 642 & 12 & $s$ & \\
\hline Earache & PC full primary care assessment and prescribing capability & 6522 & 2874 & $\checkmark$ & \\
\hline Eye, painful & $\begin{array}{l}\text { PC extended ophthalmic assessment and management capability, minor condition } \\
\text { (PEARS) }\end{array}$ & 36 & 0 & Removed & $\begin{array}{l}\text { Not appropriate for community } \\
\text { pharmacy }\end{array}$ \\
\hline Eye, painful & PC assessment and management capability, minor condition & 22 & 0 & Removed & $\begin{array}{l}\text { Not appropriate for community } \\
\text { pharmacy }\end{array}$ \\
\hline Eye, red or irritable & $\begin{array}{l}\text { PC extended ophthalmic assessment and management capability, minor condition } \\
\text { (PEARS) }\end{array}$ & 252 & 210 & $\checkmark$ & \\
\hline Eye, red or irritable & PC full primary care assessment and prescribing capability & 208 & 112 & $\checkmark$ & \\
\hline Eye, sticky or watery & $\begin{array}{l}\text { PC extended ophthalmic assessment and management capability, minor condition } \\
\text { (PEARS) }\end{array}$ & 92 & 86 & $\checkmark$ & \\
\hline Eye, sticky or watery & PC full primary care assessment and prescribing capability & 584 & 72 & $s$ & \\
\hline Eye, visual loss or disturbance & $\begin{array}{l}\text { PC extended ophthalmic assessment and management capability, minor condition } \\
\text { (PEARS) }\end{array}$ & 30 & 0 & Removed & $\begin{array}{l}\text { Not appropriate for community } \\
\text { pharmacy }\end{array}$ \\
\hline Eye, visual loss or disturbance & PC assessment and management capability, minor condition & 106 & 0 & Removed & $\begin{array}{l}\text { Not appropriate for community } \\
\text { pharmacy }\end{array}$ \\
\hline
\end{tabular}




\begin{tabular}{|c|c|c|c|c|c|}
\hline Eyelid problem & $\begin{array}{l}\text { PC extended ophthalmic assessment and management capability, minor condition } \\
\text { (PEARS) }\end{array}$ & 54 & 50 & $\checkmark$ & \\
\hline Failed contraception & PC failed contraception & 250 & 2 & $\checkmark$ & \\
\hline Failed contraception & PC full primary care assessment and prescribing capability & 22 & 20 & $\checkmark$ & \\
\hline Hair loss & PC assessment and management capability, minor condition & 6 & 6 & $\checkmark$ & \\
\hline Hair loss & PC full primary care assessment and prescribing capability & 22 & 18 & $\checkmark$ & \\
\hline Head, facial or neck injury, blunt & PC full primary care assessment and prescribing capability & 2294 & 414 & Removed & $\begin{array}{l}\text { Not appropriate for community } \\
\text { pharmacy }\end{array}$ \\
\hline Headache & PC anxiety/panic & 78 & 72 & $\checkmark$ & \\
\hline Headache & PC depressed mood & 130 & 122 & $\checkmark$ & \\
\hline Headache & PC full primary care assessment and prescribing capability & 4896 & 1496 & $\checkmark$ & \\
\hline Hearing problems or blocked ear & PC assessment and management capability, minor condition & 38 & 4 & $\checkmark$ & \\
\hline $\begin{array}{l}\text { Hip, thigh or buttock pain or } \\
\text { swelling }\end{array}$ & PC full primary care assessment and prescribing capability & 1348 & 256 & $\checkmark$ & \\
\hline Itch & PC assessment and management capability, minor condition & 104 & 90 & $\checkmark$ & \\
\hline Knee or lower leg pain or swelling & PC full primary care assessment and prescribing capability & 4948 & 704 & $\checkmark$ & \\
\hline Lower back pain & PC full primary care assessment and prescribing capability & 7660 & 1464 & $\checkmark$ & \\
\hline Lower limb pain or swelling & PC full primary care assessment and prescribing capability & 310 & 174 & $\checkmark$ & \\
\hline Mental health problem & PC anxiety/panic & 0 & 0 & Removed & $\begin{array}{l}\text { Not appropriate for community } \\
\text { pharmacy }\end{array}$ \\
\hline Mouth ulcers & PC assessment and management capability, minor condition & 100 & 90 & $\checkmark$ & \\
\hline Mouth ulcers & PC full primary care assessment and prescribing capability & 1094 & 46 & $\checkmark$ & \\
\hline Mouth ulcers & PC full dental assessment and prescribing capability & 8 & 0 & Removed & Zero NHS 111 calls \\
\hline Nasal congestion & PC assessment and management capability, minor condition & 60 & 50 & $\checkmark$ & \\
\hline $\begin{array}{l}\text { Pain and/or frequency passing } \\
\text { urine }\end{array}$ & PC assessment and management capability, minor condition & 252 & 0 & Removed & $\begin{array}{l}\text { Not appropriate for community } \\
\text { pharmacy }\end{array}$ \\
\hline Rectal pain, swelling, lump or itch & PC assessment and management capability, minor condition & 184 & 174 & $\checkmark$ & \\
\hline Rectal pain, swelling, lump or itch & PC full primary care assessment and prescribing capability & 1036 & 392 & $\checkmark$ & \\
\hline Repeat Prescription & PC repeat prescription & 872 & 850 & $\checkmark$ & \\
\hline Repeat Prescription & $\mathrm{PC}$ repeat prescription, routine & 1956 & 1876 & $\checkmark$ & \\
\hline Repeat Prescription & $\mathrm{PC}$ repeat prescription, urgent & 7118 & 6812 & $\checkmark$ & \\
\hline Scabies & PC assessment and management capability, minor condition & 8 & 8 & $\checkmark$ & \\
\hline Shoulder pain & PC full primary care assessment and prescribing capability & 1114 & 604 & $\checkmark$ & \\
\hline Skin rash & PC full primary care assessment and prescribing capability & 11,672 & 2554 & $\checkmark$ & \\
\hline
\end{tabular}




\begin{tabular}{|c|c|c|c|c|c|}
\hline Sleep difficulties & PC anxiety/panic & 14 & 12 & $\checkmark$ & \\
\hline Sleep difficulties & PC depressed mood & 42 & 30 & $\checkmark$ & \\
\hline Sore throat & PC full primary care assessment and prescribing capability & 8952 & 4978 & $\checkmark$ & \\
\hline Tiredness (fatigue) & PC anxiety/panic & 2 & 2 & $s$ & \\
\hline Tiredness (fatigue) & PC depressed mood & 12 & 10 & $\checkmark$ & \\
\hline Toe pain or swelling & PC assessment and management capability, minor condition & 0 & 0 & Removed & Zero NHS 111 calls \\
\hline Toe pain or swelling & PC full primary care assessment and prescribing capability & 1154 & 690 & $s$ & \\
\hline Toothache after dental injury & PC full dental assessment and prescribing capability & 670 & 0 & Removed & Zero NHS 111 calls \\
\hline Toothache after dental injury & PC full primary care assessment and prescribing capability & 44 & 8 & $\checkmark$ & \\
\hline Toothache without dental injury & PC full primary care assessment and prescribing capability & 64 & 0 & $\checkmark$ & \\
\hline Vaginal discharge & PC assessment and management capability, minor condition & 8 & 0 & Removed & Zero NHS 111 calls \\
\hline Vaginal discharge & PC full primary care assessment and prescribing capability & 1702 & 534 & $\checkmark$ & \\
\hline Vaginal itch or soreness & PC assessment and management capability, minor condition & 0 & 0 & Removed & Zero NHS 111 calls \\
\hline Vaginal itch or soreness & PC full primary care assessment and prescribing capability & 700 & 334 & $\checkmark$ & \\
\hline Vomiting & PC full primary care assessment and prescribing capability & 8950 & 1112 & $\checkmark$ & \\
\hline Wound problems & PC management of dressings & 2178 & 4 & $\checkmark$ & \\
\hline $\begin{array}{l}\text { Wrist, hand or finger pain or } \\
\text { swelling }\end{array}$ & PC assessment and management capability, minor condition & 0 & 0 & Removed & Zero NHS 111 calls \\
\hline $\begin{array}{l}\text { Wrist, hand or finger pain or } \\
\text { swelling }\end{array}$ & PC full primary care assessment and prescribing capability & 2088 & 896 & $\checkmark$ & \\
\hline Total NHS 111 calls & & 112,722 & 35,974 & 35,274 & \\
\hline
\end{tabular}

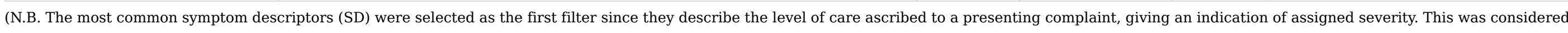

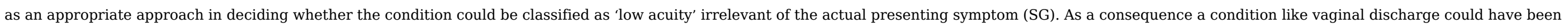

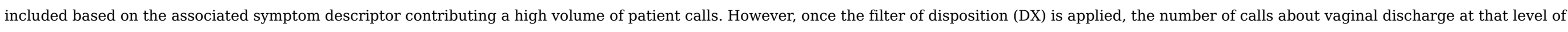

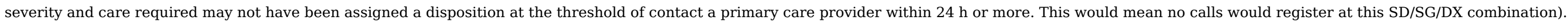

\section{Uncited reference}

\section{5.}

\section{References}

1. NHS Digital, Accident and emergency attendances in England- 2014-15, http://content.digital.nhs.uk/catalogue/PUB19883, 2016, Accessed 25 April 2017.

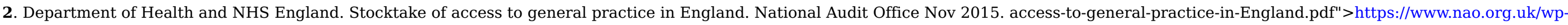
content/uploads/2015/11/Stocktake-of-access-to-general-practice-in-England.pdf; Accessed 15.04.17.

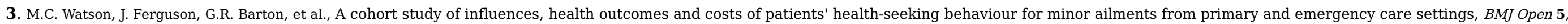


2015, e006261.

4. R. Jones, R. White, D. Armstrong, et al., Managing Acute Illness: An Enquiry into the Quality of General Practice in England, 2010, The King's Fund; London.

5. N.A. VanStone, P. Belanger, K. Moore and J.M. Caudle, Socioeconomic composition of low-acuity emergency department users in Ontario, Can Fam Physician 60, 2014 , 355-362.

6. Morken T. Welle-Nilsen, S. Hunskaar and A.G. Granas, Minor ailments in out-of-hours primary care: an observational study, Scand J Prim Health Care 29, 2011 , 39-44.

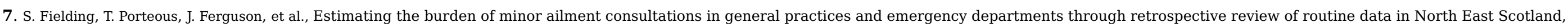
Fam Pract 32, 2015, 165-172.

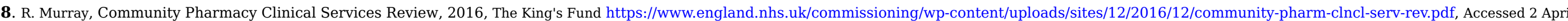
2017.

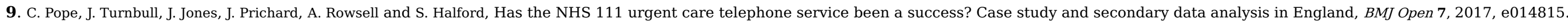

10. NHS England, Five year forward view, https://www.england.nhs.uk/wp-content/uploads/2014/10/5yfv-web.pdf, 2014 , Accessed 20 April 2017.

11. N. Harvey and C.A. Holmes, Nominal group technique: an effective method for obtaining group consensus, Int J Nurs Pract 18, $2012,188-194$.

12. A. Van de Ven and A. Delbecq, The effectiveness of nominal, delphi and interacting decision making processes, Acad Manage 12, 1974, 605-621.

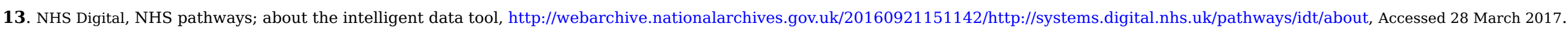

14. J. Rycroft-Malone, Formal consensus: the development of a national clinical guideline, BMJ Qual Saf 10, 2001, 238-244.

15. J.A. Cantrill, B. Sibbald and S. Buetow, The Delphi and nominal group techniques in health services research, Int J Pharm Pract 4, 1996, 67-74.

16. J. Ritchie and L. Spencer, Qualitative data analysis for applied policy research, In: A. Bryman and R.G. Burgess, (Eds.), Analysing Qualitative Data, 1994 , Routledge; London, 172-194.

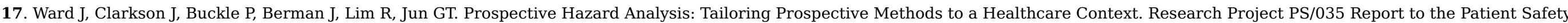
Research Programme of the Department of Health. https://www.birmingham.ac.uk/Documents/college-mds/haps/projects/cfhep/psrp/finalreports/PS035RevisedPHAFinalReportv11withToolkitJuly2010.pdf ; Accessed 20.11.17.

18. B. Franklin, N.A. Shebi and N. Barber, Failure mode and effects analysis: too little for too much?, BMJ Qual Saf 21, 2012, 607-611.

19. Y.S. Lincoln and E.G. Guba, Naturalistic Inquiry, 1985, Sage Publications; Newbury Park, CA.

20. A.M. Cavaco and P.F. Pereira, Pharmacists' counselling protocol for minor ailments: a structure-based analysis, Res Soc Adm Pharm 8, 2012, 87-100.

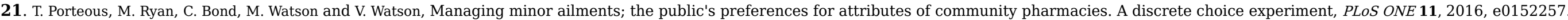

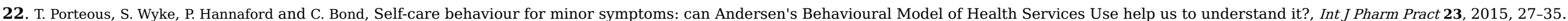

23. C. Bojke, H. Gravelle, K. Hassell and Z. Whittington, Increasing patient choice in primary care: the management of minor ailments, Health Econ 13, 2004 , 3-86.

24. L.K. Welle-Nilsen, T. Morken, S. Hunskaar and A.G. Granas, Minor ailments in out-of-hours primary care: an observational study, Scand J Prim Health Care 29, 2011 , 39-44.

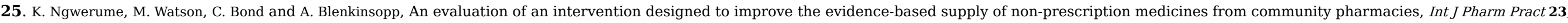
2015, 102-110

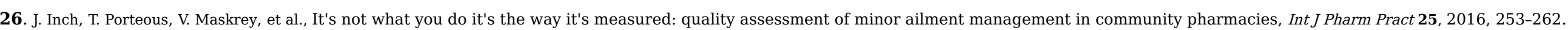

27. R. Bednall, D. McRobbie, J. Duncan and D. Williams, Identification of patients attending accident and emergency who may be suitable for treatment by a pharmacist, Fam Pract 20, $2003,54-57$. 
28. NHS Digital, General pharmaceutical services in England: 2006/07 to 2015/16, http://content.digital.nhs.uk/searchcatalogue?

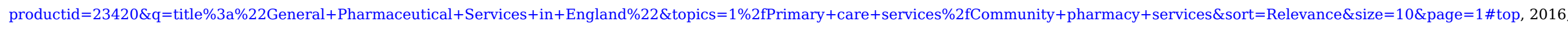
Accessed 25 March 2017.

29. Pharmacy Voice, Community pharmacy: facts and figures, http://pharmacyvoice.com/community-pharmacy/facts-and-figures/, 2017 , Accessed 24 March 2017.

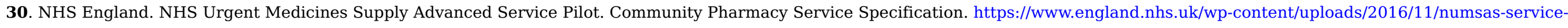
specification.pdf; Accessed 20.11.17.

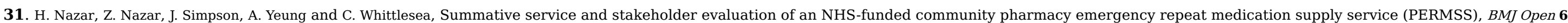
2016, e009736.

32. V. Paudyal, M.C. Watson, T. Sach, et al., Are pharmacy-based minor ailment schemes a substitute for other service providers? A systematic review, BrJ Gen Pract 63, 2013 , e472-481.

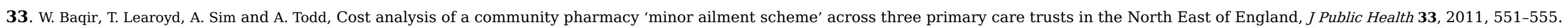

34. NICE. Clinical Knowledge Summaries (CKS). National Institute for Health and Care Excellence. https://cks.nice.org.uk/\#?char=A.; Accessed 25.03.17.

35. C.M. Kozma, C.E. Reeder and R.M. Schulz, Economic, clinical, and humanistic outcomes: a planning model for pharmacoeconomic research, Clin Ther 15, 1993 , $1121-1132$.

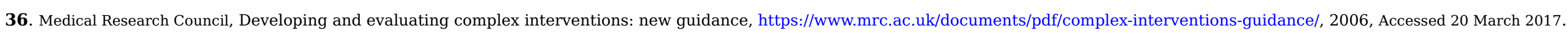

\section{Queries and Answers}

Query: Please check whether the designated corresponding author is correct, and amend if necessary.

Answer: Yes this is correct.

Query: Please check the hierarchy of the section headings.

Answer: Yes these are fine

Query: Please note that we have retained bold instead of blue in S4 Appendix(Table). Kindly check and amend if necessary.

Answer: This is fine.

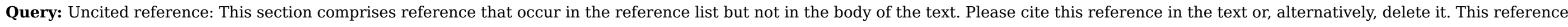
not dealt with will be retained in this section.

Answer: I have submitted an instruction to indicate where reference 15 needs to be cited

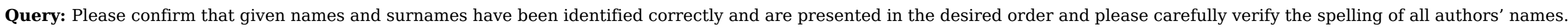
Answer: Yes 